\title{
Interaction between Angiotensin II, Osteoprotegerin, and Peroxisome Proliferator-Activated Receptor- $\gamma$ in Abdominal Aortic Aneurysm
}

\author{
Corey S. Moran ${ }^{\mathrm{a}}$ Bradford Cullen ${ }^{\mathrm{a}}$ Julie H. Campbell ${ }^{\mathrm{b}}$ Jonathan Golledge ${ }^{\mathrm{a}}$ \\ ${ }^{a}$ Vascular Biology Unit, School of Medicine, James Cook University, Townsville, Qld., ${ }^{b}$ Centre for Research in \\ Vascular Biology, University of Queensland, Brisbane, Qld., Australia
}

\section{Key Words}

Abdominal aortic aneurysm • Angiotensin II - AT1 receptor • PPAR $-\gamma \cdot$ Smooth muscle cells $\cdot$ Osteoprotegerin •

Metalloproteinase 9

\begin{abstract}
Background and Aims: Osteoprotegerin (OPG) has been associated with abdominal aortic aneurysm (AAA) expansion. Angiotensin II (Angll) receptor blockade has been shown to reduce OPG expression in human AAA tissue. Interaction between vascular Angll and OPG was further examined using cell culture and the Angll-infused $\mathrm{ApoE}^{-/-}$mouse AAA model. The ability of peroxisome proliferator-activated receptor$\gamma$ (PPAR $\gamma$ ) activation to target OPG as potential therapy for AAA was also investigated. Methods and Results: Human aortic smooth muscle cells (AoSMC) exposed to Angll exhibited dose-dependent increase in the production OPG. A 3fold increase in suprarenal aortic concentration of OPG was observed in Angll-infused ApoE-/- mice. Angll type 1 receptor expression in human AAA tissue, and AoSMC in vitro, was stimulated up 4-fold in the presence of OPG. This effect in AoSMC was counteracted in the presence of the PPAR $\gamma$ ligand, pioglitazone. Addition of PPAR $y$ ligand to cultured human AAA explant reduced OPG secretion by $60 \%$ and tissue concentration of OPG and metalloproteinase 9 by 2- and 3fold, respectively. Administration of pioglitazone to Angll-
\end{abstract}

infused $\mathrm{ApoE}^{-/-}$mice significantly reduced aortic concentrations of OPG and metalloproteinase 9. Conclusions: These data support an interaction between Angll and OPG in aneurysm formation. Activation of PPAR $\gamma$ may have a role in treatment of AAA.

Copyright $\odot 2008$ S. Karger AG, Basel

\section{Introduction}

Inflammation, proteolysis, and vascular smooth muscle cell (VSMC) loss are important mechanisms in progression of abdominal aortic aneurysm (AAA) [1]. A range of cytokines are thought to play a role in promoting aortic wall destruction [2]. We recently demonstrated high concentrations of the glycoprotein osteoprotegerin (OPG) in human AAA biopsies [3]. In vitro OPG induces development of an aneurysm phenotype in normal aortic smooth muscle cells (AoSMC) by inhibiting proliferation, promoting apoptosis and stimulating metalloproteinase (MMP) production [3]. Work by other investigators suggested a pathway by which OPG might be modulated within human aorta in both the pathological and therapeutic situations [4, 5]. Angiotensin II (AngII), thought to play an important role in AAA formation, upregulates OPG expression in human AoSMC [6]. Furthermore, the expression of OPG by VSMC is inhibited

\section{KARGER}

(C) 2008 S. Karger AG, Basel

Fax +41613061234 E-Mail karger@karger.ch www.karger.com www.karger.com/jvr
Prof. Jonathan Golledge

Vascular Biology Unit, Department of Surgery

School of Medicine, James Cook University

Townsville, Qld. 4811 (Australia)

Tel. +61 74796 1417, Fax +61 74796 1401, E-Mail jonathan.golledge@jcu.edu.au 
by activation of the nuclear receptor, peroxisome proliferator-activated receptor- $\gamma$ (PPAR $\gamma$ ) [5]. PPAR $\gamma$ has been identified as the target receptor of the thiazolidinedione group of insulin sensitizing drugs now widely used for treating type 2 diabetes [4]. In addition to influencing VSMC expression of OPG, thiazolidinediones have been shown to downregulate expression of other cytokines and proteolytic enzymes, suggesting a potential role of this medication in inhibiting progression of AAA [7].

In the present study, we investigated the link between AngII and OPG in vitro and in vivo, and hypothesized that thiazolidinediones, by downregulating OPG within AoSMC in addition to anti-inflammatory pathways, would reduce pathology associated with aortic wall degeneration and AAA expansion.

\section{Methods}

\section{Cell Culture}

Human AoSMC (Cambrex) were maintained at $37^{\circ} \mathrm{C}, 5 \%$ $\mathrm{CO}_{2}$, in culture medium (Clonetics) containing 10\% FBS. Mouse AoSMC were harvested from 17-week-old male ApoE ${ }^{-/}$C57BL/6 mice (Animal Resource Centre, Perth, Australia) using enzymic dispersion. Briefly, mice were euthanized by $\mathrm{CO}_{2}$ asphyxiation and the aorta harvested from arch to iliac bifurcation, immediately placed into chilled Hanks Balanced Salt Solution (Gibco) and cleaned. After dissection into small pieces, the aortic tissue was incubated in a sterile $1 \%$ collagenase solution at $37^{\circ} \mathrm{C}$ for $2 \mathrm{~h}$ with gentle agitation. The suspension was filtered through 63 $\mu \mathrm{m}$ sterile gauze prior to centrifugation at $200 \mathrm{~g}, 4^{\circ} \mathrm{C}$, for $5 \mathrm{~min}$. After several washes in serum-free DMEM, cells were resuspended in DMEM containing $10 \%$ FBS and maintained at $37^{\circ} \mathrm{C}, 5 \%$ $\mathrm{CO}_{2}$. Immunostain with VSMC $\alpha$-actin confirmed identity. Subconfluent AoSMC were growth arrested for $24 \mathrm{~h}$ in serum-free DMEM prior to 48-hour incubation in experimental medium containing 10\% FBS in the presence or absence of AngII $(0,0.1$, $0.5,1.0 \mu \mathrm{M})$, recombinant human OPG $(0,0.25,0.5,1.0 \mathrm{nM})$, or pioglitazone $(5.0 \mu \mathrm{M})$

\section{Human AAA Biopsies}

Informed consent was obtained for tissue collection in accordance with protocols approved by the relevant ethical bodies. Biopsies collected at surgery from 66 male patients undergoing elective repair of 5-6 cm aneurysms were obtained from the infrarenal aorta opposite the inferior mesenteric artery. Twenty biopsies were used for Western analysis $(n=6)$, and explant culture $(n=$ 14). Forty-six biopsies from patients receiving statins or AngII inhibitors were excluded due to the influence of these medications on cytokine and protease production [8].

\section{Explant Treatment and Viability}

AAA biopsies were dissected into 100-mg full-thickness explants and stabilized in DMEM $+10 \%$ FBS for $24 \mathrm{~h}$ at $37^{\circ} \mathrm{C}, 5 \%$ $\mathrm{CO}_{2}$, after which they were incubated without treatment $(\mathrm{n}=14)$, with rosiglitazone $(5 \mu \mathrm{M}, \mathrm{n}=8)$, pioglitazone $(5 \mu \mathrm{M}, \mathrm{n}=8)$, or
OPG (5 nM, n =6) over $96 \mathrm{~h}$. Medication doses used in culture were based on safe serum levels measured in patients receiving these medications [9]. Culture supernatant was collected and refreshed at 48-hour intervals and OPG and interleukin-6 (IL-6) assayed by reproducible ELISAs (R\&D Systems), following the manufacturer's protocols $[3,10]$. Tissue levels of OPG, metalloproteinase activity (MMP-2/MMP-9), and AngII type 1 receptor $\left(\mathrm{AT}_{1} \mathrm{R}\right)$ were measured in biopsies at completion of the experimental period using Western analysis and zymography. Tissue levels of ATP were compared between the incubated control, medicated explants and a further sample frozen before culture, using a commercially available bioluminescent somatic cell assay (Sigma) as per the manufacturer's instructions.

Pilot Assessment of Effect of Pioglitazone on Aneurysm

Formation in AngII-Infused ApoE ${ }^{-/-}$Mice

Approval for the animal studies was obtained from the local ethics committee. All mouse experiments were carried out in accordance with the institutional and ethical guidelines of James Cook University. Eighteen age- and sex-matched 11-week-old male $\mathrm{ApoE}^{-/-} \mathrm{C} 57 \mathrm{BL} / 6$ mice (Animal Resource Centre, Perth, Australia) were randomized to three groups: group 1 (control), group 2, and group 3. Six nonmanipulated $\mathrm{ApoE}^{-/-}$mice constituted the experimental control group (group 1). Group $2(n=6)$ received $0.1 \%$ carboxymethylcellulose suspension agent (vehicle control) in their drinking water 14 days prior to and during a 28day infusion of AngII (Sigma). Group $3(\mathrm{n}=6)$ received treatment with pioglitazone $(20 \mathrm{mg} / \mathrm{kg} /$ day $)$ in $0.1 \%$ carboxymethylcellulose suspension agent via drinking water 14 days prior to and during a 28-day infusion of AngII. AngII was delivered in sterile $0.9 \%$ saline at a rate of $1.0 \mu \mathrm{g} / \mathrm{kg} / \mathrm{min}$ via osmotic minipump (model 2004; Alzet Corporation) placed subcutaneously in the dorsal midline under ketamine $(150 \mathrm{mg} / \mathrm{kg})$ and xylazine $(10 \mathrm{mg} / \mathrm{kg})$ anesthesia. All mice were maintained on normal diet and sacrificed at 17 weeks of age by $\mathrm{CO}_{2}$ asphyxiation. Aortas were perfused with PBS via a 20-ml syringe with 20-gauge needle placed in the left ventricle, harvested from arch to iliac bifurcation and photographed with a Nikon Fujix digital camera. Maximum suprarenal aortic diameter was measured by computer aided image analysis (Scion Image, Scion Corporation). Assays for OPG, MMP-9, and PPAR $\gamma$ were compared between suprarenal aortic tissue of all animals by Western analysis (OPG/PPAR $\gamma$ ) and zymography (MMP-9). Comparative analysis specifically addressed the relationship between AngII, the presence of suprarenal aortic aneurysm and aortic levels of OPG, MMP-9, and PPAR $\gamma$, by comparing group 2 with group 1, and, separately, the effect of pioglitazone medication on the same parameters in AngII-infused mice by comparing group 3 with group 2 . Results are presented accordingly.

\section{$A T_{1}$ R-Probing with FITC-AngII}

Detection of $\mathrm{AT}_{1} \mathrm{R}$ expression in AoSMC was facilitated by an FITC-labeled AngII method adapted from Bernier and Perry [11]. Briefly, AoSMC grown on 10-mm coverslips in the presence and absence of OPG $(1.0 \mathrm{nM})$ or AngII $(100 \mu \mathrm{M})$ were fixed in $4 \%$ formaldehyde for $30 \mathrm{~s}$, air-dried, then rehydrated in PBS. Samples were washed in $1.0 \mathrm{mg} / \mathrm{ml}$ sodium metabisulfite $(3 \times 5 \mathrm{~min})$ to reduce background fluorescence and then rinsed in PBS $(3 \times$ $5 \mathrm{~min})$. Samples were then incubated with FITC-labeled AngII $(1.4 \mu \mathrm{M})$ for $2 \mathrm{~h}$ at room temperature. As controls, additional cells 


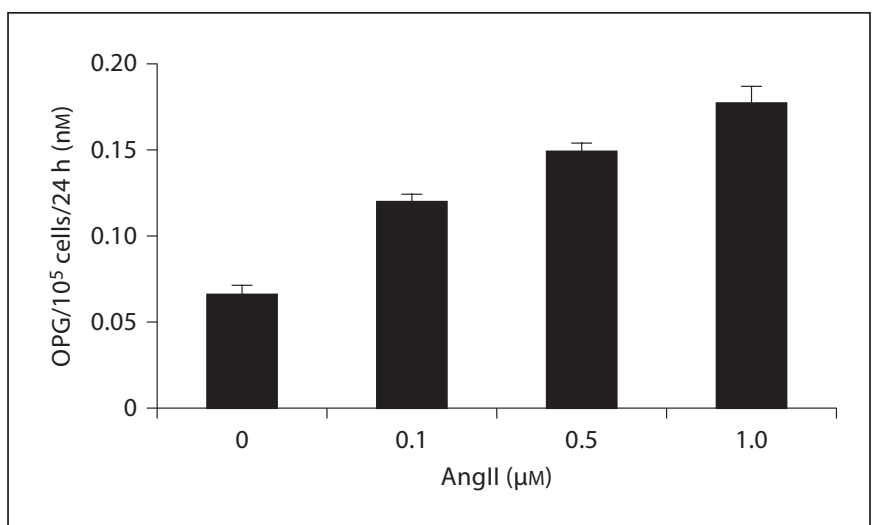

Fig. 1. Dose-dependent stimulation of OPG production in human AoSMC by AngII. Data are expressed as mean \pm SEM of seven biological repeat experiments averaged per $24 \mathrm{~h}$; $\mathrm{p}<0.001$.

were either incubated in PBS to determine background fluorescence, preincubated in $950 \mu \mathrm{M}$ Ang II solution for $10 \mathrm{~min}$ to determine nonspecific binding of FITC-labeled AngII, or pre-treated for 20 min with irbesartan $(10 \mu \mathrm{M})$ to block $\mathrm{AT}_{1} \mathrm{R}$. At completion, all coverslips were rinsed in PBS $(3 \times 5 \mathrm{~mm})$ and mounted in buffered glycerol solution containing $0.1 \% p$-phenylenediamine for fluorescence microscopy.

\section{Western Analysis}

Proteins were extracted from human and mouse aortic tissue pulverized under liquid nitrogen, and pelleted AoSMC, using chilled $1 \times$ PBS buffer containing $1 \%$ Triton X-100, 0.1\% SDS, and $10 \mathrm{mM}$ cacodylic acid. Homogenates were subjected to several liquid nitrogen freeze/thaw cycles for maximum cell rupture and tissue breakdown, prior to centrifugation at $18,000 \mathrm{~g}$ for $30 \mathrm{~min}$ at $4^{\circ} \mathrm{C}$. Protein concentration was determined using the Bio-Rad Protein Assay (Bio-Rad Laboratories). Extracted proteins from explants $(30 \mu \mathrm{g})$, AoSMC $(30 \mu \mathrm{g})$, and mouse samples $(40 \mu \mathrm{g})$ were separated using SDS gel electrophoresis (12\% SDS; Gradipore) and Western blotting carried out using either goat primary antisera for OPG (R\&D Systems Inc.; $0.2 \mu \mathrm{g} / \mathrm{ml}$ ), or rabbit primary antisera for PPAR $\gamma$ (sc-7196, Santa Cruz Biotechnology; 0.4 $\mu \mathrm{g} / \mathrm{ml}$ ) or $\mathrm{AT}_{1} \mathrm{R}$ (sc-7196, Santa Cruz Biotechnology; $0.4 \mu \mathrm{g} / \mathrm{ml}$ ). Bands were visualized using enhanced chemiluminescence (ECL Advance ${ }^{\mathrm{TM}}$; Amersham Biosciences) and identified on a ChemiDoc $^{\mathrm{TM}}$ imaging system (Bio-Rad Laboratories) supported by QuantityOne $^{\mathrm{TM}}$ 1-D Analysis Software (Bio-Rad Laboratories). Quantification of proteins was performed by comparison of band densities and expressed as mean and standard error (SEM) of relative band density units (RDU)/ $\mu$ g protein [3].

\section{Gelatin Zymography}

Zymography was performed as described previously [3]. Briefly, $10 \mu \mathrm{g}$ extracted proteins were separated at $4^{\circ} \mathrm{C}$ on a $10 \%$ acrylamide-SDS gel impregnated with $1 \mathrm{mg} / \mathrm{ml}$ gelatin, the gel washed in $2.5 \%(\mathrm{v} / \mathrm{v})$ Triton $\mathrm{X}-100$, then incubated overnight at $37^{\circ} \mathrm{C}$ in $50 \mathrm{~mm}$ Tris ( $\mathrm{pH}$ 8) containing $5 \mathrm{mM} \mathrm{CaCl}_{2}$. Bands were visualized in a $10 \%$ ethanol- $10 \%$ acetic acid solution after staining with 0.125\% Coomassie Blue, with enzyme activity quantified with
Table 1. Effect of pioglitazone medication on suprarenal aortic diameter, PPAR $\gamma$, OPG, and MMP-9 in the AngII-infused $\mathrm{ApoE}^{-/-}$mouse

\begin{tabular}{llllll}
\hline & $\mathrm{n}$ & $\begin{array}{l}\mathrm{SRA}_{\mathrm{Max}} \\
\mathrm{mm}\end{array}$ & PPAR & OPG & MMP-9 \\
\hline Group 1 & 6 & $1.11 \pm 0.03$ & $0.74 \pm 0.07$ & $0.45 \pm 0.09$ & $1.09 \pm 0.10$ \\
Group 2 & 6 & $1.78 \pm 0.27$ & $0.77 \pm 0.14$ & $1.01 \pm 0.10$ & $3.53 \pm 0.24$ \\
Group 3 & 6 & $1.33 \pm 0.31$ & $2.63 \pm 0.10$ & $0.51 \pm 0.14$ & $1.26 \pm 0.10$ \\
$\mathrm{p}^{1}$ & & 0.020 & 0.937 & 0.004 & 0.002 \\
$\mathrm{p}^{2}$ & & 0.310 & 0.002 & 0.026 & 0.002 \\
\hline
\end{tabular}

Data are expressed as mean \pm SEM; SRA $_{\text {Max }}=$ Maximum suprarenal aortic diameter; For PPAR $\gamma$, OPG and MMP-9, RDUs per microgram protein; $\mathrm{p}^{1}=$ group 2 versus group $1 ; \mathrm{p}^{2}=$ group 3 versus group 2 .

densitometric analysis using the ChemiDoc imaging system (BioRad Laboratories) and QuantityOne 1-D analysis software (BioRad Laboratories). Results are expressed as mean and SEM of $\mathrm{RDU} / \mu \mathrm{g}$ protein.

Data Analysis

The effect of increasing doses of AngII and OPG on AoSMC was assessed using the Kruskal-Wallis test. The concentration of OPG, MMP-9, and PPAR $\gamma$ within mouse suprarenal aorta, expressed as RDU/ $\mu$ g protein, was compared using Mann-Whitney $\mathrm{U}$ test between AngII-infused $(n=6)$ and nonmanipulated control mice $(n=6)$. The influence of OPG on $\mathrm{AT}_{1} \mathrm{R}$ expression in human AAA explant, and the effect of pioglitazone on the response of AoSMC, mice aorta and AAA explants were assessed using MannWhitney U test. Samples to be compared were run on the same blot or zymogram so that development conditions were comparable. The concentrations of OPG and MMPs were expressed as mean \pm SEM. Significance was assumed at a $\mathrm{p}$ value $<0.05$.

\section{Results}

AngII Stimulates OPG Production by AoSMC in vitro and Upregulates Aortic Concentrations of OPG in vivo The effects of AngII on the production of OPG in vitro using human AoSMC and in vivo within an AngII-infused animal model were examined. Incubation of human AoSMC with increasing concentrations of AngII resulted in dose-dependent production of OPG by these cells with a 3 -fold increase in OPG secretion over $48 \mathrm{~h}$ in the presence of $1.0 \mu \mathrm{M}$ AngII (fig. 1). Tissue levels of OPG and MMP-9 in the suprarenal aorta of AngII-infused $\mathrm{ApoE}^{-/-}$mice (group 2) were compared with sex- and agematched nonmanipulated $\mathrm{ApoE}^{-/-}$mice (group 1). Subcutaneous infusion of AngII over 28 days resulted in focal 

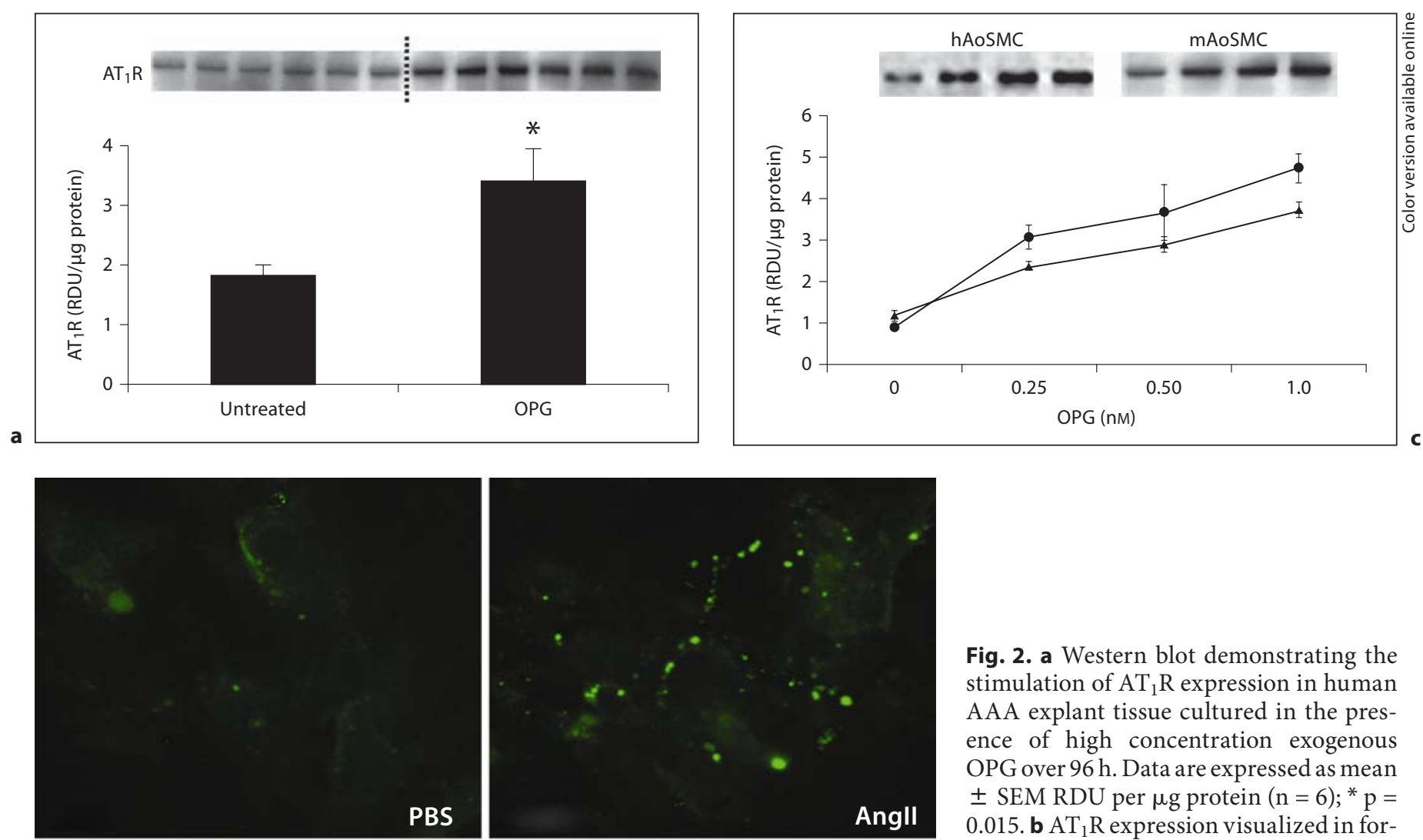

Fig. 2. a Western blot demonstrating the stimulation of $\mathrm{AT}_{1} \mathrm{R}$ expression in human AAA explant tissue cultured in the presence of high concentration exogenous OPG over $96 \mathrm{~h}$. Data are expressed as mean \pm SEM RDU per $\mu$ g protein $(n=6) ;{ }^{*} \mathrm{p}=$ 0.015. b AT $\mathrm{R}_{1}$ expression visualized in formalin-fixed AoSMC with FITC-labeled AngII. Cells were grown on coverslips over $48 \mathrm{~h}$ in the presence or absence of AngII (100 $\mu \mathrm{M}$, positive control) or OPG (1.0 $\mathrm{nM})$. After fixation, cells were incubated in PBS, or with FITC-AngII in the presence or absence of irbesartan (Irb, $10 \mu \mathrm{M}$, negative control). c Dose-dependent induction of $\mathrm{AT}_{1} \mathrm{R}$ expression in human $(\bullet)$ and murine $(\boldsymbol{\Delta})$ AoSMC by OPG over $48 \mathrm{~h}$. Data are expressed as mean \pm SEM RDU per $\mu \mathrm{g}$ protein obtained from triplicate culb
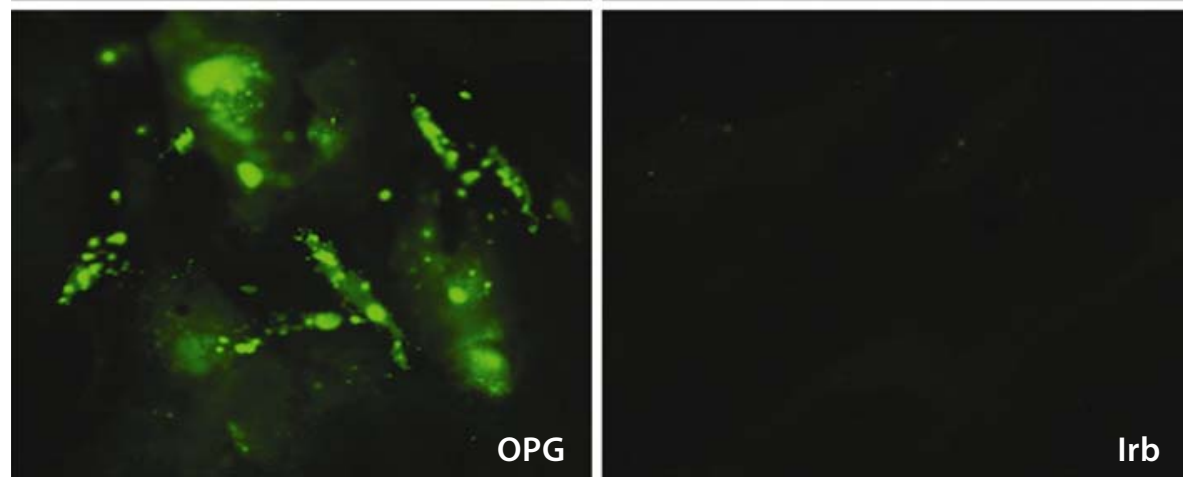
tures; $\mathrm{p}<0.01$.

Table 2. Effect of PPAR $\gamma$ activation on cytokine and MMP production in human AAA tissue ex vivo

\begin{tabular}{|c|c|c|c|c|c|c|}
\hline & $\mathrm{n}$ & OPGS & OPGT & MMP-2 & MMP-9 & IL-6 \\
\hline Control & 8 & $6.79 \pm 0.96$ & $1.02 \pm 0.10$ & $0.90 \pm 0.03$ & $1.20 \pm 0.04$ & $20.2 \pm 0.40$ \\
\hline Rosiglitazone & 8 & $2.37 \pm 0.51$ & $0.53 \pm 0.03$ & $0.90 \pm 0.05$ & $0.64 \pm 0.02$ & $17.5 \pm 0.40$ \\
\hline Pioglitazone & 8 & $3.08 \pm 0.39$ & $0.51 \pm 0.05$ & $0.90 \pm 0.07$ & $0.42 \pm 0.01$ & $17.8 \pm 0.40$ \\
\hline $\mathrm{p}^{1}$ & & 0.03 & 0.01 & 0.600 & 0.001 & 0.01 \\
\hline $\mathrm{p}^{2}$ & & 0.03 & 0.01 & 0.900 & 0.001 & 0.01 \\
\hline
\end{tabular}

Data are expressed as mean \pm SEM. OPGS = Supernatant (secreted) levels of OPG; OPGT = tissue levels of OPG; for OPGS and IL-6, picomoles per milligram tissue; for OPGT, MMP-2 and MMP-9, RDUs per microgram protein; $\mathrm{p}^{1}=$ rosiglitazone versus control; $\mathrm{p}^{2}=$ pioglitazone versus control. 
Fig. 3. Suppression of OPG-induced $A T_{1} R$ expression in human AoSMC by PPAR $\gamma$ activation. Cells incubated for $48 \mathrm{~h}$ in the presence $(+)$ or absence $(-)$ of pioglitazone (PIO, $5 \mu \mathrm{M})$ and/or OPG (1.0 nM) directly, or following a 48-hour pre-incubation ( $>$ ) with either compound. Data are expressed as mean \pm SEM of six culture experiments; ${ }^{*} \mathrm{p}=0.002$; $^{* *} \mathrm{p}<0.001$. Right panel: representative Western blots demonstrating comparative $\mathrm{AT}_{1} \mathrm{R}$ expression in treated cells ( $\mathrm{T}$; descending, OPG, PIO, $\mathrm{OPG}+\mathrm{PIO}, \mathrm{PIO} / \mathrm{OPG}, \mathrm{OPG} / \mathrm{PIO}$ ) versus untreated controls $(\mathrm{C})$.

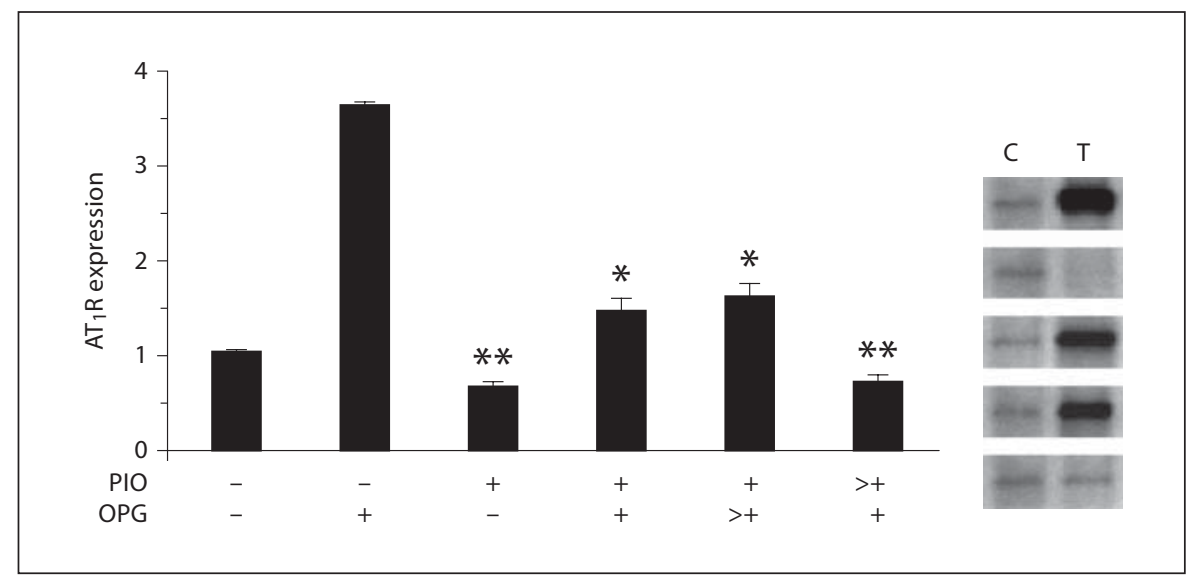

dilation of the suprarenal aorta in group 2 mice, associated with higher suprarenal aortic concentration of OPG and MMP-9 compared to group 1 mice (table 1).

\section{OPG Upregulates $A T_{1} R$ Expression in Human $A A A$}

Tissue and AoSMC in vitro

The effect of exogenous OPG on $\mathrm{AT}_{1} \mathrm{R}$ expression in human AAA tissue was examined using explant culture of AAA biopsies. Human AAA biopsies $(n=6)$ were divided into two explant specimens and each incubated in the presence of OPG or vehicle control over $96 \mathrm{~h}$. Basal secretion of OPG by AAA tissue specimens ex vivo over this time was determined at $6.79 \pm 0.96 \mathrm{pM}$ per mg tissue (table 2). Explants were subsequently incubated with an approximate 10 -fold higher concentration of exogenous OPG at $0.05 \mathrm{nM}$ per $\mathrm{mg}$ tissue. Western analysis at $96 \mathrm{~h}$ demonstrated an approximate 2 -fold increase in $\mathrm{AT}_{1} \mathrm{R}$ protein in AAA explants incubated in the presence of OPG compared to control tissue $(3.40 \pm 0.55$ vs. $1.81 \pm$ $0.20, p=0.015$; fig. $2 \mathrm{a}$ ). The presence of $\mathrm{AT}_{1} \mathrm{R}$ in human AoSMC was visualized after $48 \mathrm{~h}$ using FITC-labeled AngII, which, based on qualitative inspection, tended to be greater in cells cultured in the presence of OPG (1.0 $\mathrm{nM}$ ) compared to resting PBS-treated cells (fig. 2b). Incubation of human AoSMC and $\mathrm{ApoE}^{-/-}$mouse AoSMC with increasing concentrations of OPG resulted in a dosedependent increase in $\mathrm{AT}_{1} \mathrm{R}$ protein assessed by Western blotting after $48 \mathrm{~h}$ (fig. 2c).

\section{PPAR $\gamma$ Activation Suppresses OPG-Induced $A T_{1} R$}

Upregulation in Human AoSMC in vitro

Human AoSMC were cultured in the presence of OPG and/or pioglitazone to examine the effect of PPAR $\gamma$ activation on the action of OPG to upregulate $A_{1} R$ expres- sion. Treated cells were exposed to either pioglitazone (5 $\mu \mathrm{M})$ or OPG (1.0 $\mathrm{nM}$ ) alone, pioglitazone and OPG concurrently, OPG with addition of pioglitazone at $48 \mathrm{~h}$, or pioglitazone with addition of OPG at $48 \mathrm{~h}$. Figure 3 illustrates the significantly reduced production of $\mathrm{AT}_{1} \mathrm{R}$ protein by human AoSMC in the presence of pioglitazone regardless of post, concurrent, or prior incubation with OPG.

\section{PPAR $\gamma$-Activation Downregulates OPG, MMP-9 and IL-6 in Human AAA Biopsies}

Western analysis demonstrated the expression of PPAR $\gamma$ within human AAA biopsies (data not shown). The effect of PPAR $\gamma$ activators on OPG and MMP-9 production in human AAA explants was examined. Human AAA biopsies were divided into three explant specimens and incubated each in the presence of pioglitazone $(5 \mu \mathrm{M})$, rosiglitazone $(5 \mu \mathrm{M})$, or vehicle control over $96 \mathrm{~h}$. Explant tissue ATP levels at $96 \mathrm{~h}$ were comparable with that of control specimens snap frozen before culture, thus confirming specimen viability during culture (control tissue, $0.48 \pm 0.11 \mu \mathrm{g} \mathrm{ATP} / \mathrm{mg}$ tissue; untreated explant, $0.57 \pm 0.08 \mu \mathrm{g} \mathrm{ATP} / \mathrm{mg}$ tissue; pioglitazone, $0.51 \pm 0.07$ $\mu \mathrm{g} \mathrm{ATP} / \mathrm{mg}$ tissue; rosiglitazone, $0.53 \pm 0.12 \mu \mathrm{g} \mathrm{ATP} / \mathrm{mg}$ tissue). Treatment of AAA explant with PPAR $\gamma$ ligand resulted in the reduction of both OPG and MMP-9. The amount of OPG secreted in a 24 -hour period in the presence of PPAR $\gamma$ ligands was reduced by $60 \%$ compared to untreated explant, and corresponded with a 2 -fold decrease in tissue OPG demonstrated by Western analysis at $96 \mathrm{~h}$ (table 2). The effect of PPAR $\gamma$ activation on MMP9 within AAA tissue was most marked in explants incubated with pioglitazone in which MMP-9 was decreased 3 -fold compared to untreated explants (table 2). No effect 


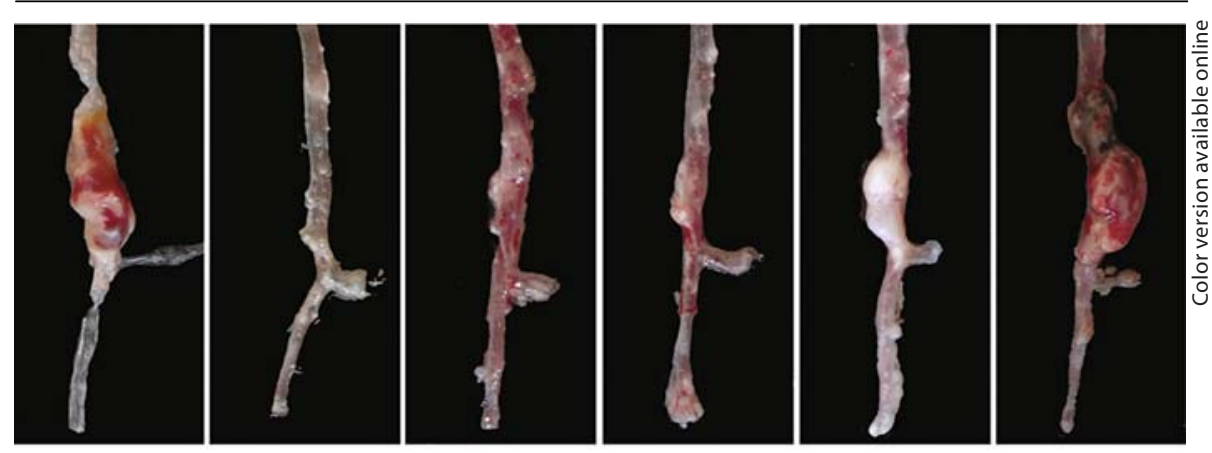

\section{Group 3}

Fig. 4. Morphology of suprarenal aorta harvested from $\mathrm{ApoE}^{-/-}$mice subcutaneously infused with AngII over 28 days (group 2), compared with corresponding aortic region from AngII-infused mice medicated with pioglitazone 14-days prior to and during AngII infusion (group 3).

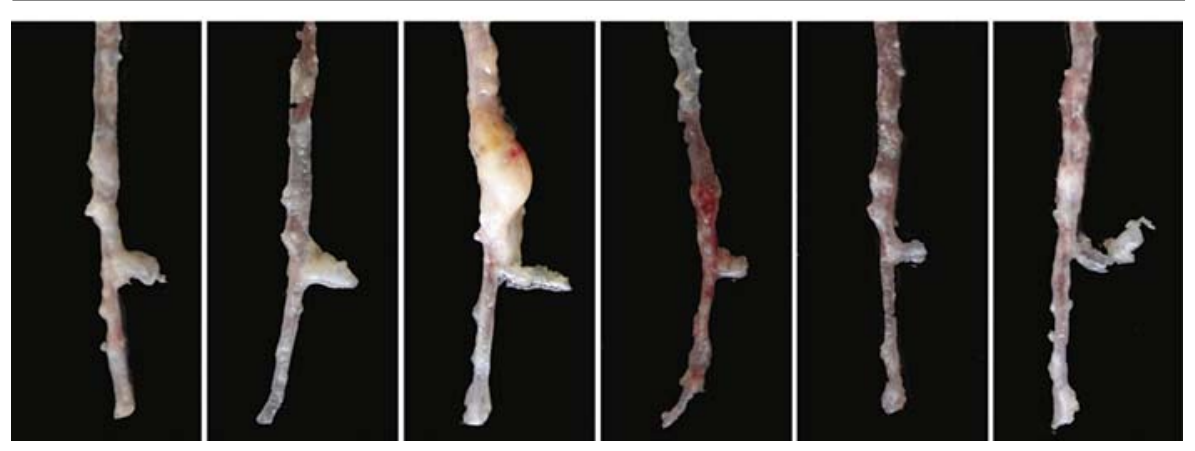

of pioglitazone or rosiglitazone on MMP-2 was observed. A modest yet statistically significant decrease in IL- 6 secretion of $15 \%$ was demonstrated for explants exposed to PPAR $\gamma$ ligands (table 2).

\section{PPAR $\gamma$ Activation in vivo Downregulates OPG and MMP-9 within the Suprarenal Aorta of AngII-Infused ApoE ${ }^{-/-}$Mice}

Protein level of PPAR $\gamma$ within the suprarenal aorta of nonmedicated AngII-infused group 2 mice determined using Western analysis was not significantly different from levels in group 1 mice (table 1). The administration of pioglitazone to AngII-infused $\mathrm{ApoE}^{-/-}$mice (group 3) was associated with a significant 3 -fold increase in suprarenal aortic concentration of PPAR $\gamma$ compared to group 2 animals (table 1). Inspection of the suprarenal aorta from group 2 and 3 mice suggested that focal dilatation was more common in group 2 animals (fig. 4). However, maximum suprarenal diameter was not significantly different (table 1). Pioglitazone treatment resulted in 2-fold lower mean suprarenal aortic OPG concentration than that measured in the nonmedicated group 2 animals (table 1). A similar effect was observed for MMP-9 (92 kDa) with pioglitazone reducing the MMP activity within the suprarenal aorta by approximately $65 \%$ (table 1).

\section{Discussion}

Present evidence suggests that smaller AAA measuring $40-55 \mathrm{~mm}$ should not undergo surgical intervention [12]. However, approximately $60 \%$ of these expand to a diameter requiring invasive treatment if managed conservatively [1]. A medication which can inhibit the pathological changes characteristic of AAA would thus have great potential value both for patients with small AAA and those with large aneurysm not suitable for invasive treatment. We previously identified high concentrations of the glycoprotein OPG in biopsies of human AAA and demonstrated the ability of OPG to stimulate pathological processes integral to AAA progression in vitro at concentrations present within human biopsies [3]. In the present study, we provide evidence to support an interaction between AngII and OPG in AAA development. We also present preliminary data from both human AAA tis- 
sue and a mouse model to support the value of PPAR $\gamma$ activation in regulating aneurysm development.

The ability of AngII to promote inflammation and proteolysis, its effect in stimulating aneurysm formation in vivo, and the high concentration of AngII forming enzymes in human AAA biopsies, support an instrumental role for this peptide in the pathogenesis of AAA [13-15]. Based on our earlier observation of elevated levels of OPG protein present in human AAA tissue [3], we speculated that AngII upregulated aortic OPG in vivo and employed a mouse model of AAA to examine our hypothesis. A number of murine models of AAA have been developed $[13,16-18]$. The $\mathrm{ApoE}^{-/-}$mouse develops focal weakening primarily affecting the suprarenal aorta when infused subcutaneously with AngII [13, 19]. A limiting factor in this model is that formation of aortic aneurysm often involves destruction of the internal elastic lamina and focal dissection of the aortic wall rather than the circumferential medial destruction seen in human AAA [20]. However, despite morphological differences, there are significant correlations between this mouse model of AAA and the human condition, including the importance of male gender, inflammation and proteolysis [20,21]. Furthermore, physical manipulation of the aorta required in other models is not required.

Consistent with previous reports [13, 19], we demonstrated focal aortic dilatation within the suprarenal region in $\mathrm{ApoE}^{-/-}$mice infused with AngII. Concentrations of OPG detected within suprarenal aortic tissue of these animals were significantly higher than in corresponding tissue from $\mathrm{ApoE}^{-/-}$mice not infused with AngII. The ability of AngII to upregulate OPG was confirmed in human AoSMC (fig. 1). We also demonstrated higher activity of MMP-9 in AngII-infused mice compared to controls. We reported previously that OPG acts to upregulate MMP-9 both in VSMC and monocytic cells in vitro [3] . Whether the in vivo upregulation of aortic MMP-9 induced by AngII infusion seen in this study was secondary to OPG upregulation is uncertain. OPG was originally characterized as regulator of bone remodeling by virtue of its ability to act as a decoy receptor for receptor activator of nuclear factor $\kappa \mathrm{B}$ ligand (RANKL) and inhibit osteoclastogenesis [22]. A direct-effector function of OPG was later demonstrated by Theoleyre et al. [23], whereby proMMP-9 activity was enhanced in purified osteoclasts via activation of the ras-MAP kinase pathway, involving phosphorylation of $\mathrm{p} 38$ and ERK1/2, upon the binding of OPG to a preformed RANK-RANKL duplex at the cell membrane. Both RANK and RANKL are expressed in diseased vasculature by VSMC, endothelial cells, and in- flammatory cells [24]. Therefore, it is plausible that formation of the RANK-RANKL-OPG tertiary complex on VSMC and macrophages in vivo contributes to the increase in MMP-9 demonstrated here in AngII-infused mouse aorta.

We report here that incubation of human AAA tissue and AoSMC in the presence of exogenous OPG increased expression of the AngII receptor, $\mathrm{AT}_{1} \mathrm{R}$, by up to 2 - and 4-fold, respectively (fig. 2). Most cardiovascular effects of AngII are mediated via $\mathrm{AT}_{1} \mathrm{R}$ and expression of the receptor in VSMC is upregulated in atherosclerotic disease [25]. Expression of $\mathrm{AT}_{1} \mathrm{R}$ is associated with activation of the MAP kinase and NFкB transduction pathways [26, 27], and, as mentioned above, OPG is able to stimulate MAP kinase signaling upon formation of a tertiary complex with cell membrane-bound RANK-RANKL [23]. Thus, our observation of increased $\mathrm{AT}_{1} \mathrm{R}$ levels in AAA explant can be explained in terms of stimulated expression resulting from exogenous OPG binding to RANKRANKL duplexes already formed on inflammatory, endothelial, and remaining smooth muscle cells present within the diseased tissue. However, the mechanism by which OPG stimulates $\mathrm{AT}_{1} \mathrm{R}$ expression in AoSMC in vitro remains unclear. Attributing this novel finding to signaling via the tertiary complex RANK-RANKL-OPG is improbable, as RANK and RANKL are frequently undetectable in normal vessels [24] and thus unlikely to be expressed in AoSMC in vitro. We have reported direct regulatory action of OPG on growth and survival of normal VSMC in vitro previously [3]. This, together with the current finding with respect to $\mathrm{AT}_{1} \mathrm{R}$ expression, suggests that OPG possesses the ability to exert direct biological action in VSMC independent of the RANK-RANKL system. For example, it may activate signaling at the cell membrane via an as yet undefined receptor pathway, or, as a soluble molecule, may function intracellularly to influence processes associated with $\mathrm{AT}_{1} \mathrm{R}$ upregulation at a transcription/translation level. This remains the subject of ongoing investigation in our laboratory.

Activation of the nuclear transcription factor PPAR $\gamma$ has previously been shown to downregulate $\mathrm{AT}_{1} \mathrm{R}$ expression in VSMC [7, 28, 29], and, OPG gene expression in human AoSMC [5]. In line with these reports, we observed that pioglitazone inhibited the induction of $\mathrm{AT}_{1} \mathrm{R}$ by OPG in human AoSMC (fig. 3), an effect most likely mediated via the PPAR $\gamma$ activator's action on $\mathrm{AT}_{1} \mathrm{R}$ or OPG expression, or both. These findings prompted us to examine the effect of PPAR $\gamma$ activation on human AAA explants and in the AngII-infused $\mathrm{ApoE}^{-/-}$mouse model of AAA. 
We documented the effect of AngII blockade on human AAA explant production of OPG in an earlier report [3]. Treatment of explants with the $\mathrm{AT}_{1} \mathrm{R}$ antagonist, irbesartan, resulted in the time-dependent inhibition of OPG secretion highlighting the potential for $\mathrm{AT}_{1} \mathrm{R}$ blockade in slowing aneurysm expansion. Interestingly, $\mathrm{AT}_{1} \mathrm{R}$ antagonists have recently been shown to induce PPAR $\gamma$ activity [30]. In the present study, we detected PPAR $\gamma$ protein within human AAA tissue (data not shown). Incubation of human AAA biopsies with PPAR $\gamma$ ligands resulted in a 2.5 -fold decrease in OPG production, a 3 fold decrease in MMP-9, together with a small reduction in IL-6 production (table 2). Whether thiazolidinedioneinduced down-regulation of OPG synthesis in the AAA biopsies resulted from direct action of PPAR $\gamma$ activation upon OPG gene expression [5], or indirectly via negative regulation of $\mathrm{AT}_{1} \mathrm{R}$ and the AngII pathway [28], is not clear from the present data. Even so, the data do support the potential benefit of PPAR $\gamma$ activation in regulating aneurysm progression in vivo, which we examined using the AngII-infused mouse model.

Examination of the suprarenal aorta in the pioglitazone-treated group 3 mice demonstrated varying degrees of focal dilatation (fig. 4), and whether the gross pattern differed significantly when compared to the nonmedicated group 2 mice was subjective. Morphometric analysis did determine a lower mean maximum suprarenal aortic diameter in group 3 mice compared to group 2 (table 1), although statistical significance could not be demonstrated. Within the suprarenal aortic tissue however, OPG concentration (and MMP-9) was significantly decreased in mice receiving pioglitazone treatment (table 1). Nonetheless, the small number of mice per experimental group $(n=6)$ prevented definitive conclusions being drawn with respect to the effect of PPAR $\gamma$ activation on aneurysm development within this model, and further study incorporating a larger experimental cohort is presently underway in our laboratory to address this issue.
Low concentrations of PPAR $\gamma$ were detected in control and AngII-infused $\mathrm{ApoE}^{-/-}$mice in line with previous studies [31]. Administration of pioglitazone via drinking water 14 days prior to the start of AngII infusion and continuing for the duration of the infusion period resulted in upregulation of aortic PPAR $y$ expression. Although an increase in protein does not necessarily equate to an increase in levels of the active transcription factor, the fact that associated with this change we found significant downregulation of aortic OPG and MMP-9 suggests that $\mathrm{AT}_{1} \mathrm{R}$ and/or OPG gene regulation by PPAR $\gamma$ is present.

The ability of $\mathrm{AT}_{1} \mathrm{R}$ antagonists to inhibit OPG production, inflammation and proteolysis suggests these medications may be useful in slowing aneurysm progression. Many patients with AAA are already prescribed $\mathrm{AT}_{1} \mathrm{R}$ blockers or AngII converting enzyme inhibitors for the management of hypertension, making these medications difficult to investigate in a randomized controlled clinical trial. The present study describes a potential positive feedback mechanism by which OPG, via AngII and $\mathrm{AT}_{1} \mathrm{R}$, sustains its own production within the aortic wall, which could favor cellular changes associated with aneurysm progression. The ability of PPAR $\gamma$ activation to block this positive feedback loop suggests the potential for its activation within the aortic wall in limiting AAA progression. Synthetic PPAR $\gamma$ agonists are available for clinical use but not presently indicated in patients with AAA, and further studies examining the effect of this medication in aneurysmal disease are warranted.

\section{Acknowledgements}

Funding from the National Institute of Health, USA (RO1 HL080010-01), and NHMRC (project grant 379600) supported this work. C.S.M. was supported by a Fellowship (PF05B2217) from the National Heart Foundation of Australia. J.G. holds a Practitioner's Fellowship from the NHMRC, Australia (431503).
References
Golledge J, Muller J, Daugherty A, Norman P: Abdominal aortic aneurysm: pathogenesis and implications for management. Arterioscler Thromb Vasc Biol 2006;26:26052613.

2 Shimizu K, Libby P, Mitchell RN: Local cytokine environments drive aneurysm formation in allografted aortas. Trends Cardiovasc Med 2005; 15:142-148.

\footnotetext{
-3 Moran CS, McCann M, Karan M, Norman PE, Ketheesan N, Golledge J: Association of osteoprotegerin with human abdominal aortic aneurysm progression. Circulation 2005;111:3119-125.

4 Martens FM, Visseren FL, Lemay J, de Koning EJ, Rabelink TJ: Metabolic and additional vascular effects of thiazolidinediones. Drugs 2002;62:1463-1480.
} 
5 Fu M, Zhang J, Lin Yg Y, Zhu X, Willson TM, Chen YE: Activation of peroxisome proliferator-activated receptor $\gamma$ inhibits osteoprotegerin gene expression in human aortic smooth muscle cells. Biochem Biophys Res Commun 2002;294:597-601.

-6 Zhang J, Fu M, Myles D, Zhu X, Du J, Cao X, Chen YE: PDGF induces osteoprotegerin expression in vascular smooth muscle cells by multiple signal pathways. FEBS Lett 2002; 521:180-184.

7 Tao L, Liu HR, Gao E, Teng ZP, Lopez BL, Christopher TA, Ma XL, Batinic-Haberle I, Willette RN, Ohlstein EH, Yue TL: Antioxidative, antinitrative, and vasculoprotective effects of a peroxisome proliferator-activated receptor- $\gamma$ agonist in hypercholesterolemia. Circulation 2003;108:2805-2811.

$\checkmark 8$ Cipollone F, Fazia M, Iezzi A, Pini B, Cuccurullo C, Zucchelli M, de Cesare D, Ucchino S, Spigonardo F, De Luca M, Muraro R, Bei R, Bucci M, Cuccurullo F, Mezzetti A: Blockade of the AngII type 1 receptor stabilizes atherosclerotic plaques in humans by inhibiting prostaglandin E2-dependent matrix metalloproteinase activity. Circulation 2004; 109:1482-1488.

$\checkmark 9$ Budde K, Neumayer HH, Fritsche L, Sulowicz W, Stompor T, Eckland D: The pharmacokinetics of pioglitazone in patients with impaired renal function. Br J Clin Pharmacol 2003;55:368-374.

10 Clancy P, Oliver L, Jayalath R, Buttner P, Golledge J: Assessment of a serum assay for quantification of abdominal aortic calcification. Arterioscler Thromb Vasc Biol 2006; 26:2574-2576.

-11 Bernier NJ, Perry SF: Angiotensins stimulate catecholamine release from the chromaffin tissue of the rainbow trout. Am J Physiol 1997;273:R49-R57.

-12 UK Small Aneurysm Trial Participants: Mortality results for randomised controlled trial of early elective surgery or ultrasonographic surveillance for small abdominal aortic aneurysms. Lancet 1998;352:16491655.

13 Daugherty A, Manning MW, Cassis LA: AngII promotes atherosclerotic lesions and aneurysms in apolipoprotein E-deficient mice. J Clin Invest 2000;105:1605-1612.
14 Nishimoto M, Takai S, Fukumoto H, Tsunemi K, Yuda A, Sawada Y, Yamada M, Jin D, Sakaguchi M, Nishimoto Y, Sasaki S, Miyazaki M, et al: Increased local AngII formation in aneurysmal aorta. Life Scie 2002;71: 2195-2205.

15 Davies MJ: Aortic aneurysm formation: lessons from human studies and experimental models. Circulation 1998;98:193-195.

16 Pyo R, Lee JK, Shipley JM, Curci JA, Mao D, Ziporin SJ, Ennis TL, Shapiro SD, Senior RM, Thompson RW: Targeted gene disruption of matrix metalloproteinase-9 (gelatinase B) suppresses development of experimental abdominal aortic aneurysms. J Clin Invest 2000;105:1641-1649.

17 Daugherty A, Cassis LA: Chronic AngII infusion promotes atherogenesis in low density lipoprotein receptor ${ }^{-/-}$mice. Ann N Y Acad Sci 1999;892:108-118.

18 Manning MW, Cassis LA, Huang J, Szilvassy SJ, Daugherty A: Abdominal aortic aneurysms: fresh insights from a novel animal model of the disease. Vasc Med 2002;7:4554

19 Gavrila D, Li WG, McCormick ML, Thomas M, Daugherty A, Cassis LA, Miller FJ Jr, Oberley LW, Dellsperger KC, Weintraub NL: Vitamin E inhibits abdominal aortic aneurysm formation in angiotensin II-infused apolipoprotein E-deficient mice. Arterioscler Thromb Vasc Biol 2005;25:1671-1677.

20 Saraff K, Babamusta F, Cassis LA, Daugherty A: Aortic dissection precedes formation of aneurysms and atherosclerosis in angiotensin II-infused, apolipoprotein E-deficient mice. Arterioscler Thromb Vasc Biol 2003; 23:1621-1626.

21 Daugherty A, Cassis LA: Mouse models of abdominal aortic aneurysms. Arterioscler Thromb Vasc Biol 2004;24:429-434.

-22 Simonet WS, Lacey DL, Dunstan CR, Kelly M, Chang MS, Luthy R, Nguyen HQ, Wooden S, Bennet L, Boone T, Shimamoto G, DeRose M, et al: Osteoprotegerin: a novel secreted protein involved in the regulation of bone density. Cell 1997;89:309-319.

23 Theoleyre S, Wittrant Y, Couillaud S, Vusio P, Berreur M, Dunstan C, Blanchard F, Redini F, Heymann D: Cellular activity and signalling induced by Osteoprotegerin in osteoclasts: involment of receptor activator of nuclear factor $\mathrm{\kappa B}$ ligand and MAPK. Biochim Biophys Acta 2004;1644:1-7.
24 Collin-Osdoby P: Regulation of vascular calcification by osteoclast regulatory factors RANKL and osteoprotegerin. Circ Res 2004; 95:1046-1057.

-25 Schieffer B, Schieffer E, Hilfiker-Kleiner D, Hilfiker A, Kovanen PT, Kaartinen M, Nussberger J, Harringer W, Drexler H: Expression of AngII and interleukin 6 in human coronary atherosclerotic plaques: potential implications for inflammation and plaque instability. Circulation 2000;101:1372-1378.

26 Martin MM, Buckenberger JA, Jiang J, Malana GE, Knoell DL, Feldman DS, Elton TS: TGF-beta1 stimulates human AT1 receptor expression in lung fibroblasts by cross talk between the Smad, p38 MAPK, JNK, and PI3K signaling pathways. Am J Physiol Lung Cell Mol Physiol 2007;293:L790-L799.

27 Cowling RT, Gurantz D, Peng JF, Dillmann WH, Greenberg BH: Transcription factor $\mathrm{NF}-\kappa \mathrm{B}$ is necessary for up-regulation of type 1 angiotensin II receptor $\mathrm{mRNA}$ in rat cardiac fibroblasts treated with tumor necrosis factor- $\alpha$ or interleukin-1 $\beta$. J Biol Chem 2002; 277:5719-5724

28 Sugawara A, Takeuchi K, Uruno A, Ikeda Y, Arima S, Kudo M, Sato K, Taniyama Y, Ito S: Transcriptional suppression of type 1 AngII receptor gene expression by peroxisome proliferator-activated receptor-gamma in vascular smooth muscle cells. Endocrinology 2001;142:3125-3134.

29 Sugawara A, Takeuchi K, Uruno A, Kudo M, Sato K, Ito S: Effects of mitogen-activated protein kinase pathway and co-activator CREP-binding protein on peroxisome proliferator-activated receptor- $\gamma$-mediated transcription suppression of AngII type 1 receptor gene. Hypertens Res 2003;26:623628.

$>30$ Schupp M, Janke J, Clasen R, Unger T, Kintscher U: Angiotensin type 1 receptor blockers induce peroxisome proliferator-activated receptor-gamma activity. Circulation 2004;109:2054-2057.

-31 Tham DM, Martin-McNulty B, Wang YX, Wilson DW, Vergona R, Sullivan ME, Dole W, Rutledge JC: AngII is associated with activation of NF-kappaB-mediated genes and downregulation of PPARs. Physiol Genomics $2002 ; 11: 21-30$. 